\title{
Disponibilidade hídrica e fertilização orgânica em plântulas de maracujazeiro amarelo
}

\section{Seedling response of passion fruit to levels of irrigation and organic fertilization}

\author{
Danila Lima Araújo ${ }^{1}$; Mario Leno Martins Véras ${ }^{2}$; Lunara de Sousa Alves ${ }^{3}$; Diva Lima de Araújo ${ }^{4}$ Raimundo Andrade $^{5}$
}

Resumo - A produção sustentável de mudas é de essencial importância para a sanidade de produções futuras das culturas, entre elas está principalmente as frutíferas, onde, uma boa muda resulta posteriormente em uma boa fornecedora de frutos de qualidade. Assim, objetivou-se avaliar o desenvolvimento inicial de mudas de maracujazeiro amarelo sob ação de níveis de água disponível e aplicação de fertilizante orgânico a base de urina de vaca. O delineamento experimental utilizado foi inteiramente casualizado $(5 \times 2)$ com cinco repetições, totalizando 50 unidades experimentais; os tratamentos consistiram da combinação de cinco níveis de água disponível (60; 70; 80; 90 e 100 \%), 1 - com a aplicação (C) e 2 - sem a aplicação (S) de solução a base de urina de vaca. Todas as variáveis estudadas nas mudas de maracujazeiro responderam linearmente a disponibilidade hídrica imposta a elas, de acordo com que se aumentou a água disponível os resultados foram incrementados, já com e sem a aplicação de solução a base de urina de vaca, não surtiram efeitos significativos.

Palavras-chave: mudas, estresse hídrico, urina de vaca

\begin{abstract}
Sustainable production of seedlings is essential to the sanity of future crop yields, among them is mainly the fruit, where a good change subsequently results in a good supplier of quality fruits. Thus, the objective was to evaluate the initial development of seedlings was yellow under the action of water levels available, application of organic fertilizer based on cow urine. The experimental design was completely randomized $(5 \times 2)$ with five replicates, totaling 50 experimental units , treatments were combinations of five levels of water available (60, 70, 80, 90 and 100\%), 1 with the application (C) 2 and without the application (s) based solution cow urine. All variables in seedlings was linearly responded to water availability imposed on them, according to which increased the water available the results were increased, as with and without the application of solution -based cow urine, did not produce significant effects .
\end{abstract}

Keywords: seedlings, water stress, cow urine

\footnotetext{
*Autor para correspondência

Recebido em 25/02/2014 e aceito em 19/02/2015

${ }^{1}$ Mestranda em Engenhari Agrícola, área de concentração em Irrigação e Drenagem (UFCG). E-mail: danilalimaraujo@hotmail.com

${ }^{2}$ Graduado, UEPB, Catolé do Rocha - PB, Email: mario.deus1992@bol.com.br

${ }^{3}$ Graduada, UEPB, Catolé do Rocha, PB, Email: lunara_alvesuepb@ hotmail.com

${ }^{4}$ Graduada em licenciatura em Ciências Agrárias, UEPB, Mestra em Eng. agrícola -UFCG, Doutora em Engenharia Agrícola - UFCG. Catolé do Rocha - PB,

Email: dyvaaraujo@gmail.com

${ }^{5}$ Prof. Doutor, Depart. De Ciências Agrárias e Exatas, UEPB, Catolé do Rocha, PB
} 


\section{INTRODUÇÃO}

O maracujá (Passiflora eduliz f. flavicarpa Degener) é considerado botanicamente como planta trepadeira (ARAÚJO et al., 2011). Tem enorme relevância econômica para o Brasil, em que o país ocupa o ranking de maior produtor mundial de maracujá (VIANA et al., 2012). Dentre as regiões que produzem mais maracujá o Nordeste está entre eles e os principais estados produtores são: Bahia, Espírito Santo, São Paulo, Rio de Janeiro, Ceará e Sergipe (AGRIANUAL, 2006). Das 479.813 toneladas produzidas no Brasil o Nordeste é responsável por cerca da metade da produção (AGRIANUAL, 2008).

O potássio está entre os principais nutrientes, ocupando o segundo lugar entre os mais absorvidos no desenvolvimento dessa cultura (CARVALHO et al., 1999).

Dentre os fertilizantes aplicados no crescimento do maracujá, encontra-se a urina de vaca, que é rica em vários nutrientes como fósforo, potássio, cálcio, magnésio, enxofre, ferro, manganês, boro, cobre, zinco, sódio, cloro, cobalto, molibdênio, alumínio e fenois (PESAGRO - RIO, 2001). Na cultura do maracujá a quantidade de urina de vaca que deve ser aplicada é de meio litro por planta (PESAGRO - RIO, 2002).

Para a produção de mudas, os recipientes recomendados são os sacos de polietileno que permitem armazenar um bom volume de substrato proporcionando boa formação das mudas de alta qualidade para o plantio (RIBEIRO et al., 2005). O viveiro surge como uma opção viável para a formação de mudas de maracujá, uma vez que, proporciona um sombreamento maior antes do transplantio (MELETTI, 1994).

O substrato é considerado um dos fatores essenciais para obtenção de mudas de boa qualidade (PEIXOTO, 1986), por oferecerem melhores condições do sistema radicular se desenvolver bem (WAGNER JÚNIOR et al., 2006).

A pouca disponibilidade de água no solo pode prejudicar o desenvolvimento do maracujá, ocasionando a queda das folhas e frutos (VASCONCELOS et al., 2013) Por se tratar de uma cultura que requer altas quantidades de água, às vezes, para cumprir as necessidades hídricas, recomenda-se a aplicação de 10 litros de água por dia (ARAÚJO et al., 2000; SILVA \& KLAR, 2002; SOUSA et al., 2003).

Nesse sentido o objetivo dessa pesquisa foi de avaliar o comportamento de mudas de maracujá submetidas a diferentes níveis de água disponível no solo com e sem aplicação de urina de vaca em condições de casa de vegetação no semiárido paraibano.

\section{MATERIAL E MÉTODOS}

O experimento foi conduzido em local protegido (viveiro) na Universidade Estadual da Paraíba - Campus IV na cidade de Catolé do Rocha, realizado de 1 de agosto a 6 de setembro de 2013. O delineamento utilizado foi o inteiramente casualizado (DIC), com análise em esquema fatorial (5 x 2) com 5 repetições, totalizando 50 unidades experimentais. O estudo correspondeu em avaliar 2 tipos de fornecimento de irrigação com solução a base de urina de vaca (correspondendo a 1\% do conteúdo aplicado) e sem solução a base de urina de vaca onde a irrigação foi feita com água provinda de um poço amazonas existente na universidade, e 5 níveis de disponibilidade hídrica $(60 ; 70 ; 80 ; 90$ e 100\% água disponível (AD) no substrato). O solo e húmus de minhoca utilizados para fazer o substrato foram adquiridos no próprio campus sendo misturados em $50 \%$ cada (1:1).

A água utilizada na irrigação apresenta condutividade elétrica de $0,8 \mathrm{dS} / \mathrm{m}$. A análise da água foi realizada pelo Laboratório de Irrigação e Salinidade (LIS) do Centro de Tecnologia e Recursos Naturais da Universidade Federal de Campina Grande - UFCG. E apresentou as seguintes características químicas: $\mathrm{pH}=7,53 ;$ Cálcio $=2,30$ $\left(\mathrm{cmol}_{\mathrm{c}} / \mathrm{dm}^{3}\right)$. Magnésio $=1,56\left(\mathrm{cmol}_{\mathrm{c}} / \mathrm{dm}^{3}\right) ;$ Sódio $=4,00$ $\left(\mathrm{cmol}_{\mathrm{c}} / \mathrm{dm}^{3}\right) ;$ Potássio $=0,02\left(\mathrm{cmol}_{\mathrm{c}} / \mathrm{dm}^{3}\right)$; Cloreto $=3,90$ $\left(\mathrm{cmol}_{\mathrm{c}} / \mathrm{dm}^{3}\right)$; Carbonato $=0,57\left(\mathrm{cmol}_{\mathrm{c}} / \mathrm{dm}^{3}\right) ;$ Bicarbonato $=$ $3,85\left(\mathrm{cmol}_{\mathrm{c}} / \mathrm{dm}^{3}\right) ; \mathrm{RAS}=2,88\left(\mathrm{mmol}_{\mathrm{c}} \mathrm{L}^{-1}\right)^{1 / 2}$ e Classificação Richards (1954) com $\mathrm{C}_{3} \mathrm{~S}_{1}$.

O método de irrigação utilizado foi o manual, sendo que a reposição das lâminas de água às mudas foi realizado pelo processo de pesagem, fornecendo, durante as 24 horas, a cada tratamento, o volume equivalente a lâmina de água evaporada com base no dia anterior. Na determinação da umidade do solo, utilizou-se o método padrão de estufa a circulação forçada de ar, sendo baseado na diferença de peso em uma amostra em que se deseja determinar a umidade antes e após a secagem, a uma temperatura de $110^{\circ} \mathrm{C}$. Utilizou-se um recipiente com capacidade para $3 \mathrm{~kg}$ de solo hermeticamente fechado para evitar perdas por evaporação, colocando água até saturar o solo, posteriormente, após 48 horas, coletou-se uma amostra úmida. A referida amostra foi pesada e colocada para secar na estufa, durante 48 horas, após e, a secagem, pesou-se novamente e calculou-se a porcentagem de umidade do solo pela seguinte equação (MANTOVANI et al., 2007). Capacidade de Campo

$U B S=\left(\frac{M 1-M 2}{M 2-M 3}\right) * 100$

UBS=Umidade em Base Úmida;

$\mathrm{M}_{1}=$ Peso do solo úmido + peso da cápsula;

$\mathrm{M}_{2}=$ Peso do solo seco + peso da cápsula;

$\mathrm{M}_{3}=$ Peso da cápsula de amostragem

Conforme substrato empregado apresentou as seguintes características: Umidade em base úmida: 52,26\%.

O substrato foi submetido a $52,26 \%$ (100\% de AD); 47,03\% (90\% de AD); 41,80\% (80\% de AD); 36,58\% (70\% de $\mathrm{AD})$ e $31,35 \%(60 \% \mathrm{AD})$ no solo, sendo que cada recipiente recebeu $2 \mathrm{~kg}$ de substrato seco.

Os valores quantificados em conteúdo de água no solo através de pesagens diariamente em balança de precisão do conteúdo total de água no solo e calculado o volume de água a ser aplicado em cada recipiente para que fosse mantida a umidade do solo correspondente aos tratamentos estudados, de acordo com a equação descrita:

$V R=C C-C A$

Onde:

$\mathrm{VR}=$ Volume de água a aplicar

$\mathrm{CC}=$ Peso do solo determinado para cada tratamento

$\mathrm{CA}=$ Peso do solo atual. 
Tabela 1. Distribuição dos tratamentos e níveis de reposição de água com base na lâmina de água evaporada no dia anterior

\begin{tabular}{ccc}
\hline $\begin{array}{c}\text { Água Disponível no } \\
\text { solo (\% vol) }\end{array}$ & Maracujazeiro & gramas \\
\cline { 2 - 3 } 70 & & 2316-CA \\
80 & $2369-\mathrm{CA}$ \\
90 & $2421-\mathrm{CA}$ \\
100 & $2474-\mathrm{CA}$ \\
\hline
\end{tabular}

O solo utilizado no experimento apresentou as seguintes características químicas: Cálcio $=4,63\left(\mathrm{cmol}_{\mathrm{c}} / \mathrm{dm}^{3}\right)$; Magnésio $=2,39\left(\mathrm{cmol}_{\mathrm{c}} / \mathrm{dm}^{3}\right) ;$ Sódio $=0,30\left(\mathrm{cmol}_{\mathrm{c}} / \mathrm{dm}^{3}\right)$; Potássio $=0,76\left(\mathrm{cmol}_{\mathrm{c}} / \mathrm{dm}^{3}\right)$; Soma de bases $-\mathrm{SB}=8,08$ $\left(\mathrm{cmol}_{\mathrm{c}} / \mathrm{dm}^{3}\right)$; Hidrogênio $=0,00\left(\mathrm{cmol}_{\mathrm{c}} / \mathrm{dm}^{3}\right) ;$ Alumínio $=$ $0,00\left(\mathrm{cmol}_{\mathrm{c}} / \mathrm{dm}^{3}\right) ; \mathrm{CTC}=8,08$ e matéria orgânica $=1,88 \%$.

$\mathrm{Na}$ análise química da urina de vaca os elementos químicos presentes são: $\mathrm{N}=20,32 \mathrm{~g} \mathrm{~kg}^{-1} ; \mathrm{P}=0,0076 \mathrm{~g} \mathrm{~kg}^{-1} \mathrm{e}$ $\mathrm{K}=7,19 \mathrm{~g} \mathrm{~kg}^{-1} ; \mathrm{Ca}=0,33 \mathrm{~g} \mathrm{~kg}^{-1} ; \mathrm{Mg}=0,95 \mathrm{~g} \mathrm{~kg}^{-1} ; \mathrm{Fe}=0,55$ $\mathrm{mg} \mathrm{kg}{ }^{-1} ; \mathrm{Mn}=0,1 \mathrm{mg} \mathrm{kg}^{-1} ; \mathrm{Cu}=0,05 \mathrm{mg} \mathrm{kg}^{-1}$ e $\mathrm{Zn}=0,1 \mathrm{mg}$ $\mathrm{kg}^{-1}$.

Os dados foram analisados e interpretados a partir das análises de variância (Teste $\mathrm{F}$ ) e pelo confronto de médias do teste de TUKEY, através do programa SISVAR conforme metodologia de FERREIRA (2007).

DC

A

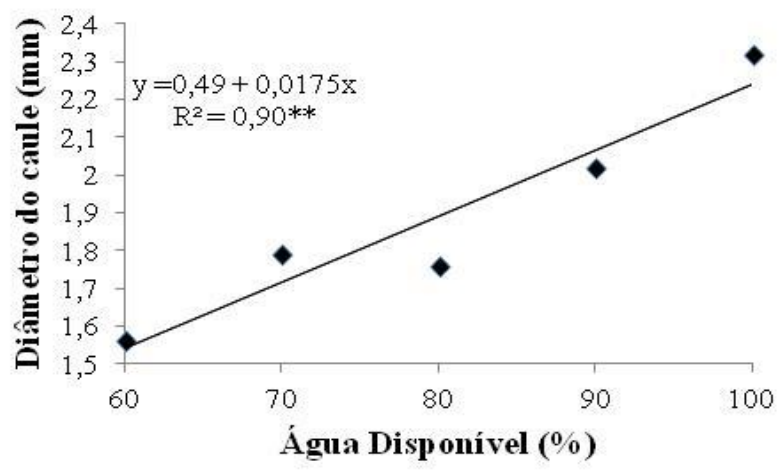

\section{RESULTADOS E DISCUSSÃO}

O diâmetro do caule (DC), a altura da planta (AP) e o número de folhas (NF) foram afetados significativamente pela aplicação de diferentes níveis de água disponível no solo de forma que o nível de significância foi de $(p<0,01)$ de probabilidade para todas as variáveis, todas se comportando linearmente. Os maiores resultados encontrados foram com $100 \%$ de $\mathrm{AD}$ obtendo em média os valores de 2,32 mm; 2,75 $\mathrm{cm}$ e 2,57 respectivamente.

Concordando com os dados de Butrinowski et al. (2013) que encontrou resultados crescentes para o diâmetro do caule e altura da planta de acordo com o implemento de níveis de irrigação em mudas de eucalipto. Bessa (2010) trabalhando com cultivares de girassol sob estresse hídrico constatou os maiores diâmetros nas plantas que receberam o tratamento com a maior lâmina. Araújo (2012) também encontrou resultados lineares crescentes para o diâmetro caulinar do girassol de acordo com o aumento gradativo da disponibilidade de água no solo.

AP

B

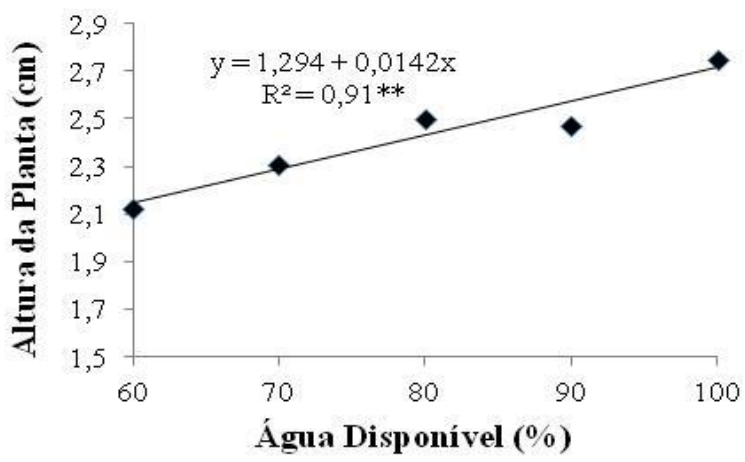

NF $\quad \mathrm{C}$

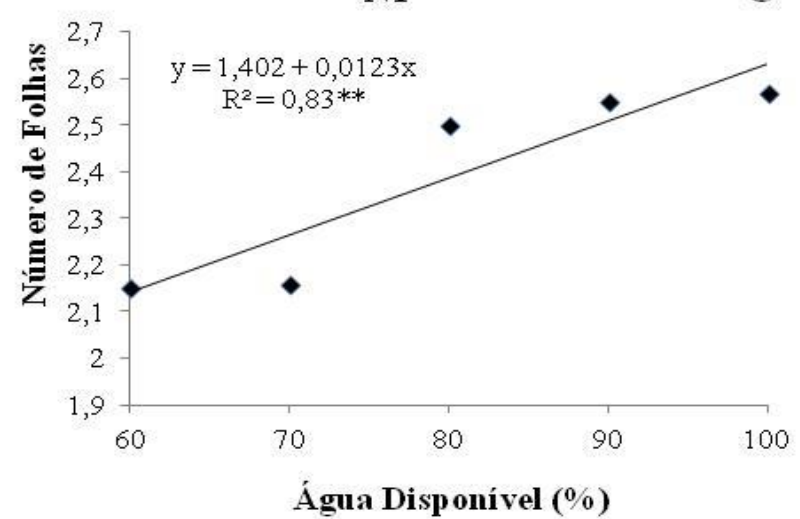

Figura 1. Diâmetro do caule (DC) (A), Altura da Planta (AP) (B) e Número de Folhas (NF) (C) de mudas de maracujazeiro submetidos à Níveis de Água Disponível 
Resultado encontrados por Silva et al. (2013), estudando plântulas de feijão-cupi notou a diminuição no comprimento da parte aérea com a limitação hídrica. Gabialtti et al. (2005) em seu trabalho constatou que ao colocar $100 \%\left(\mathrm{~L}_{2}\right)$ o número de folhas aumentou para as mudas de limão volkamericano, corroborando com os resultados encontrados na pesquisa.

Pode-se verificar para o peso verde das folhas (PVF) e peso verde da raiz (PVR), resultados significativos a nível de $(\mathrm{p}<0,01)$, ambas se enquadrando no tipo de regressão linear crescente, de forma que ao se aumentar a disponibilidade de água incrementou-se também o peso verde das folhas e da raiz corroborando com Araújo (2012) que encontrou resultados lineares crescentes para o peso fresco das folhas de girassol ao aumentar gradativamente a disponibilidade de água no solo.
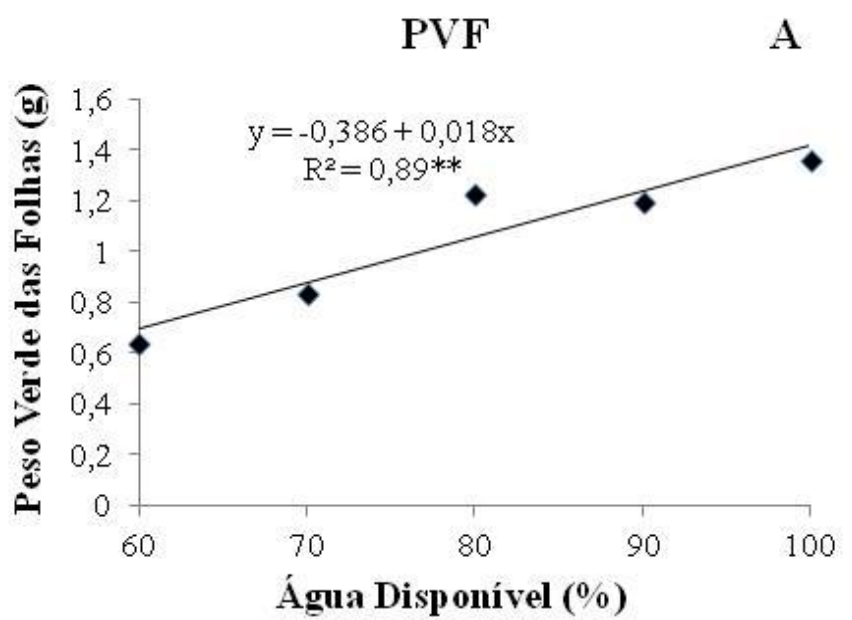

PVR B

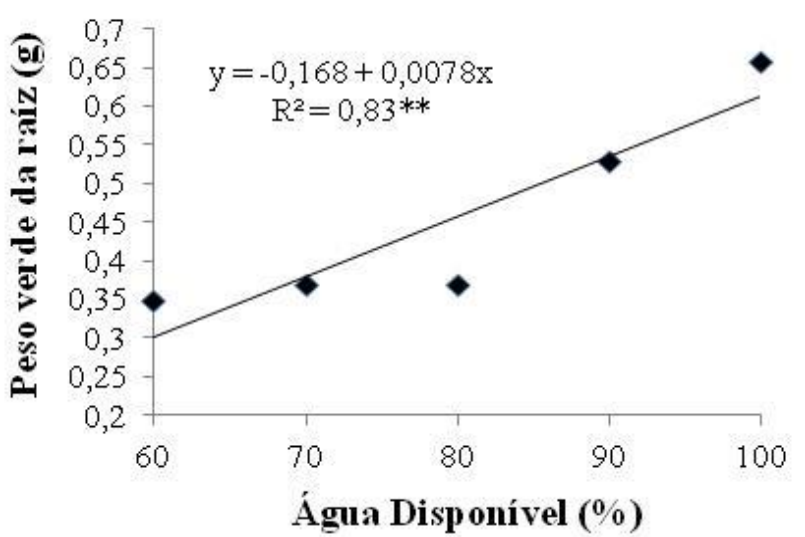

Figura 2. Peso Verde da Folha (PVF) (A) e Peso Verde da Raiz (PVR) (B), de mudas de maracujazeiro submetidos à Níveis de Água Disponível

O mesmo comportamento pode ser constatado para o peso verde da parte aérea (PVPA) e peso verde total (PVT) que se comportaram de forma linear crescente de acordo com que se incrementou a disponibilidade de água no substrato. Butrinowski et al. (2013), ao trabalhar lâminas de irrigação na produção de mudas de eucaliptos também constatou que de acordo com o aumento de disponibilidade de água, a produção de fitomassa fresca da parte aérea foi incrementada. Sobrinho et al. (2011), avaliando a influência de diferentes níveis de água $(100 ; 90 ; 80 ; 70$ e $60 \%$ da capacidade de campo) no solo sobre a cultura do girassol, a massa fresca da parte aérea das plantas foi ajustada ao modelo de regressão quadrático e regressão linear, resultados também vistos por Araujo (2012) que ao trabalhar água disponível no solo para o girassol, encontrou incremento de acordo com aumentou a disponibilidade de água no solo. Oliveira et al. (2012) também trabalhando com girassol sob níveis de água disponível no solo constatou resultados semelhantes.

Na Tabela 2 estão os resultados com e sem aplicação de solução a base de urina de vaca onde se pode verificar que nenhuma das variáveis estudadas foram afetadas significativamente pelo teste comparação de médias (teste Tukey).
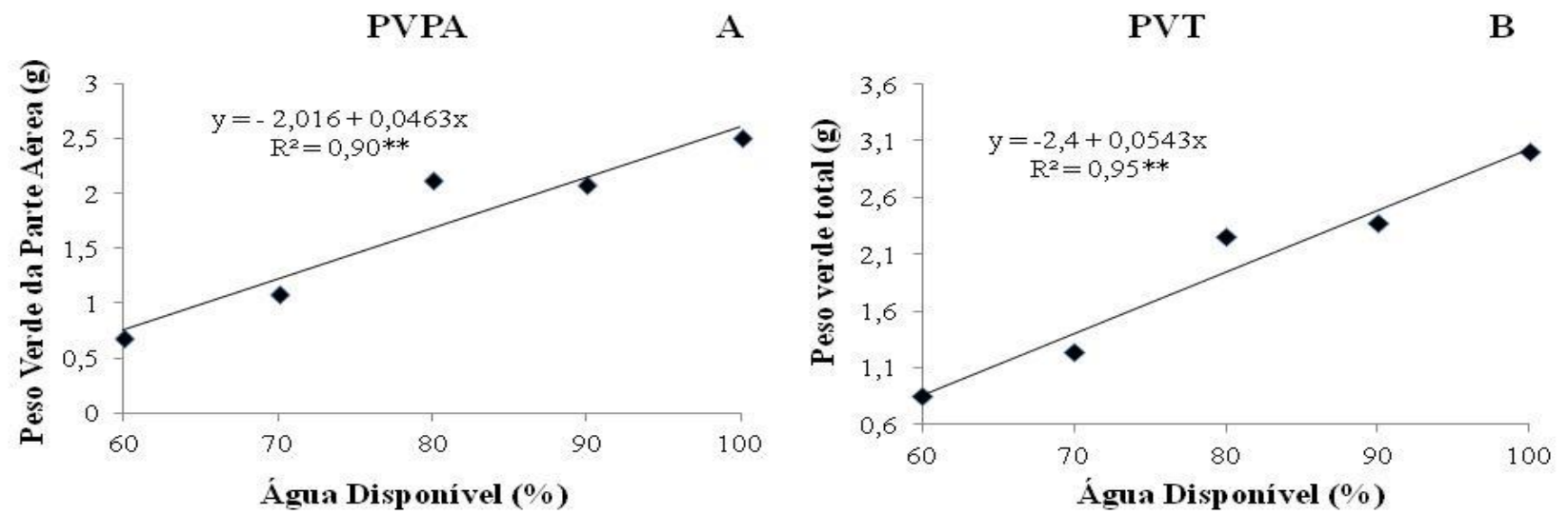

Figura 3. Peso Verde da Parte Aérea (PVPA) (A) e Peso Verde Total (PVT) (B), de mudas de maracujazeiro submetidos à Níveis de Água Disponível 
Tabela 2. Médias referentes ao diâmetro do caule (DC), altura da planta (AP), número de folhas (NF), peso verde das folhas (PVF), peso verde da raiz (PVR), peso verde da parte aérea (PVPA) e peso verde total (PVT) com e sem aplicação de urina de vaca

\begin{tabular}{|c|c|c|c|c|c|c|c|}
\hline Fonte de variação & & & & $\mathrm{Me}$ & & & \\
\hline & $\mathrm{DC}$ & AP & $\mathrm{NF}$ & PVF & PVR & PVPA & PVT \\
\hline Com urina & $1,88 \mathrm{~A}$ & $2,47 \mathrm{~A}$ & $2,36 \mathrm{~A}$ & $1,05 \mathrm{~A}$ & $0,42 \mathrm{~A}$ & $1,55 \mathrm{~A}$ & $1,27 \mathrm{~A}$ \\
\hline Sem urina & $1,90 \mathrm{~A}$ & $2,39 \mathrm{~A}$ & $2,41 \mathrm{~A}$ & $1,09 \mathrm{~A}$ & $0,49 \mathrm{~A}$ & $1,82 \mathrm{~A}$ & $1,34 \mathrm{~A}$ \\
\hline
\end{tabular}

Médias seguidas de mesma letra na coluna não diferem a 5\% de probabilidade pelo teste de Tukey

Observa-se para todas as variáveis que não diferenciaram estatisticamente com e sem a aplicação da solução a base de urina de vaca, obtendo-se resultados semelhantes tanto com a aplicação quanto sem a aplicação.

Para a maioria das variáveis sem a aplicação de urina resultaram nos maiores valores. Podendo ter havido disponibilidade suficiente de nutrientes no substrato $(50 \%$ de solo $+50 \%$ de húmus de minhoca), que juntamente com a disponibilidade máxima de água satisfez as necessidades hídricas e nutricionais das mudas de maracujazeiro. Resultados semelhantes foram encontrados por Mesquita et al. (2012), que trabalhando com estresse salino com e sem aplicação de biofertilizante como fertilizante orgânico não encontraram diferença significativa. Diferentemente de Barros (2011), que encontrou interações significativas entre tipos de substrato e adubação foliar.

\section{CONCLUSÕES}

1 - A lâmina de irrigação de $100 \%$ de água disponível proporciona melhor crescimento em mudas de maracujazeiro.

2 - A aplicação ou não de solução nutritiva a base de urina de vaca não influencia no maracujazeiro.

\section{REFERÊNCIAS BIBLIOGRÁFICAS}

AGRIANUAL 2006 - Anuário da Agricultura Brasileira. São Paulo, FNP Consultoria \& Comércio. 2006. p. 370-375: (Maracujá).

AGRIANUAL 2008 - Anuário da Agricultura Brasileira. São Paulo, FNP Consultoria \& Agroinformativos (FNP) p. 502.

ARAÚJO, D. L. Comportamento do girassol à adubação fosfatada e água disponível em um argissolo. 75f. Dissertação (Mestrado em Engenharia Agrícola) UFCG, 75p. 2012.

ARAUJO, D. C. et al. Efeito do volume de água e da cobertura morta sobre o crescimento inicial do maracujazeiro- amarelo amarelo. Revista Brasileira de Engenharia Agrícola e Ambiental, v.4, n.1. p.121- 124. 2000 .

ARAUJO, J. dos S. S.; ANDRADE, R.; LINHARES, A. S. F.; SILVA, Uilma L. da; MAIA FILHO, F. das C. F.; MESQUITA, E. F. de. Efeito da Adubação Orgânica na Avaliação da Fitomassa de Mudas de Maracujazeiro Amarelo. Resumos... Cadernos de Agroecologia - ISSN 2236-7934 - Vol 6, No. 2, Dez 2011.
BARROS, C. M. Substratos e adubação foliar com biofertilizante na produção de mudas de maracujazeiro e mamoeiro. UNICENTRO-PR. (Dissertação de mestrado), 71 p. 2011.

BESSA, M. C. Crescimento e produtividade do girassol sob diferentes lâminas de irrigação. 2010, 76p. Monografia. Universidade Federal do Ceará, Fortaleza

BUTRINOWSKI, R. T. BUTRINOWSKI, I. T. SANTOS, E. L. PICOLLOTO, R. A. SANTOS, R. F. Disponibilidade hídrica no desenvolvimento inicial de mudas de Eucalyptus grandes em ambiente protegido. Acta Iguazu, Cascavel, v.2. n. 3, p. 84-93, 2013.

CARVALHO, A. J. C. de; MARTINS, D. P.; MONERAT, P. H.; BERNADO, S. Produtividade e qualidade do maracujazeiro-amarelo em resposta à adubação potássica sob lâminas de irrigação. Revista Brasileira de Fruticultura, Cruz das Almas, v.21, n.3, p.333-337, 1999.

FERREIRA, D. F. Sisvar Versão 5.0. Lavras: UFLA, 2007.

GABIATTI, J. A. CAVALCANTE, I. H. L. CALZAVARA, S. A. SILVA, V. L. Substrato e lâminas de irrigação em duas espécies cítricas. Irriga. Botucatu, v.10. n. 4, 341348, 2005.

MANTOVANI, E. C. BERNARDO, S. PALARETTI, L. F. Irrigação: princípios e métodos. 2. ed. Viçosa, Ed. UFV, p.358, 2007.

MELETTI, L. M. M. Maracujá: a qualidade da muda é essencial. O Agronômico, Campinas, v. 46, n.1/3, p. 9$12,1994$.

MESQUITA, F. O. REBEQUI, A. M. CAVALCANTI, L. F. SOUTO, A. G. L. Crescimento absoluto e relativo de mudas de maracujazeiro sob biofertilizante e águas salinas. Revista de Ciências Agrárias, vol. 35 nº Lisboa, 2012.

OLIVEIRA, J. T. L. CHAVES, L. H. G. CAMPOS, V. B. SANTOS JÚNIOR, J. A. GUEDES FILHO, D. H. Fitomassa do girassol cultivado sob adubação nitrogenada e níveis de água disponível. Revista Brasileira de Agricultura Irrigada- Fortaleza, v. 6, $\mathrm{n}^{\mathrm{o}} .1$, p.23-32, 2012.

PEIXOTO, J. R. Efeito da matéria orgânica, do superfosfato simples e do cloreto de potássio na formação de mudas de maracujazeiro (Passiflora eduliz f. flavicarpa 
Degener). Lavrasm UFLA, 1986, 101p. (Tese de mestrado).

PESAGRO. Urina de vaca: alternativa eficiente e barata. Niterói, 2001. 8 p. (PESAGRO. Documento, 68).

PESAGRO-RIO (2002) Urina de vaca: alternativa eficiente e barata. Rio de Janeiro, Documentos, n. 96. 8p

RIBEIRO, M. C. C.; MORAIS, M. J. A. de; SOUSA, A. H. de; LINHARES, P. C. F.; BARROS JÚNIOR, A.P. Produção de mudas de maracujá-amarelo com diferentes substratos e recipientes. Caatinga, Mossoró, v.18, n.3, p.155-158, jul./set. 2005.

SILVA, A. A. G.; KLAR, A. E. Demanda hidrica do maracujazeiro-amarelo (Passiflora edulis Sims f. flavicarpa Deg.). Irriga, v.7, n.3, 2002.

SILVA, C. S. PEREIRA, J. S. TELES, V. O. CAMARA, F. T. Efeito de disponibilidade de água na germinação e no desenvolvimento inicial de plântulas de feijão-caupi. Enciclopédia Biosfera, Centro Científico ConhecerGoiânia, v. 9. N. 16, p.2984. 2013.

SOBRINHO, S. P.; TIEPPO, R. C.; SILVA, T. J. A. Desenvolvimento inicial de plantas de girassol em condições de estresse hídrico. Enciclopédia Biosfera, v. 7, n. 12, p. 1-12, 2011.

SOUSA, V. F. et al. Produtividade do maracujazeiro amarelo sob diferentes níveis de irrigação e doses de potássio via fertirrigação. Pesquisa Agropecuária Brasileira, v.38, n.4, p.497-504, 2003.

VASCONCELOS, D. V.; SOUSA, V. F. de; VIANA, T. V. de A.; AZEVEDO, B. M. de; SOUSA, G. G. DE; JÚNIOR, J. A. H. C. Interação entre níveis de irrigação e fertirrigação potássica na cultura do maracujazeiro. Irriga, Botucatu, v. 18, n. 1, p. 160-170, janeiro-março, 2013.

VIANA, P. C.; LIMA, J. G. A.; ALVINO, F. C. G.; JÚNIOR, J. R. de S.; GOMES, E. C.; VIANA, K. C.; Efeito da salinidade da água de irrigação na produção de maracujazeiro-amarelo. ACSA - Agropecuária Científica no Semi-Árido, v.8, n.1, p 45-50, jan - mar, 2012.

WAGNER JÚNIOR, A.; ALEXANDRE, R. S.; NEGREIRO, J. R.; PIMENTEL, L. D.; COSTA E SILVA, J. O.; BRUCKNER, C. H. Influência do substrato na germinação e desenvolvimento inicial de plantas de maracujazeiro amarelo (Passiflora edulis Sims f. flavicarpa Deg). Ciência e Agrotecnologia, Lavras, v. 30, n. 4, 2006. 